Gut, 1965, 6, 407

\title{
Assessment of a new inlet device for use in gastric hypothermia
}

\author{
L. H. BLUMGART ${ }^{1}$, F. D. NAYLOR, AND H. L. DUTHIE \\ From the University Department of Surgery, Royal Infirmary, Sheffield
}

EDITORIAL SYNOPSIS This device ensures more even cooling of the canine stomach producing neither solid freezing nor gross mucosal damage. The communication offers no support for the clinical use of gastric hypothermia for duodenal ulcer but suggests that this technique might be appropriate in treating massive gastrointestinal haemorrhage.

The three years since the introduction of 'gastric freezing' by Wangensteen and his associates (Wangensteen, Peter, Nicoloff, Walder, Sosin, and Bernstein, 1962a; Wangensteen, Peter, Bernstein, Walder, Sosin, and Madsen, 1962b; Peter, Bernstein, Sosin, Madsen, Walder, and Wangensteen, 1962) have witnessed a mounting scepticism as regards its safety and efficacy (McIlrath, Hallenbeck, Allen, Mann, Baldes, Brown, and Rovelstad, 1963; Blumgart, Kay, Naylor, and Kugler, 1964; Karacadag and Klotz, 1964; White, Hightower, and Adalid, 1964; Scott, Shull, O'Neill, and Richie (1964); Artz, McFarland, and Fitts, 1964; Lippman, Morgenstern, and Panish, 1964). It has been clearly shown (Blumgart et al., 1964; Lippman et al., 1964) that grossly uneven cooling of the stomach leading to focal freezing and subsequent gastric ulceration are mainly due to the standard system of inlet tubing which allows 'jetting' of the inflowing coolant against the balloon wall.

A new system of inlet tubing is reported which eliminates this 'jetting' effect and produces more even cooling of the stomach without gross mucosal damage.

\section{MATERIALS AND METHODS}

The O.E.M. F.90 gastric hypothermia machine ${ }^{2}$ was used for this study. The modified 'foam-baffled' inlet system of tubing used is shown in Figure 1. The inflow tubing ends in an elongation perforated above and below an internal air-filled balloon which is inflated via a thin catheter running within the outflow tubing. The perforations are 'baffled' by a layer of plastic foam which effectively eliminates jetting of the inflowing coolant. The

1Medical Research Council fellow.

shampaine Industries.

A tube to this design suitable for clinical use should soon be available from Portland Plastics, Hythe, Kent. internal balloon, together with the plastic strut, serve to keep the tubing system away from the balloon wall. The thermistor placed within the tubing system at the neck of the balloon registers the temperature of the fluid leaving the balloon.

\section{ASSESSMENT OF THE NEW INLET DEVICE}

GASTRIC 'FREEZING' EXPERIMENTS Ten dogs were subjected to a standardized freezing procedure (outflow temperature at the neck of the balloon $-9^{\circ} \mathrm{C}$. to $-11^{\circ} \mathrm{C}$. for one hour), during which gastric temperatures were continuously recorded by means of thermistors placed in the submucosa. Details of the technique have been

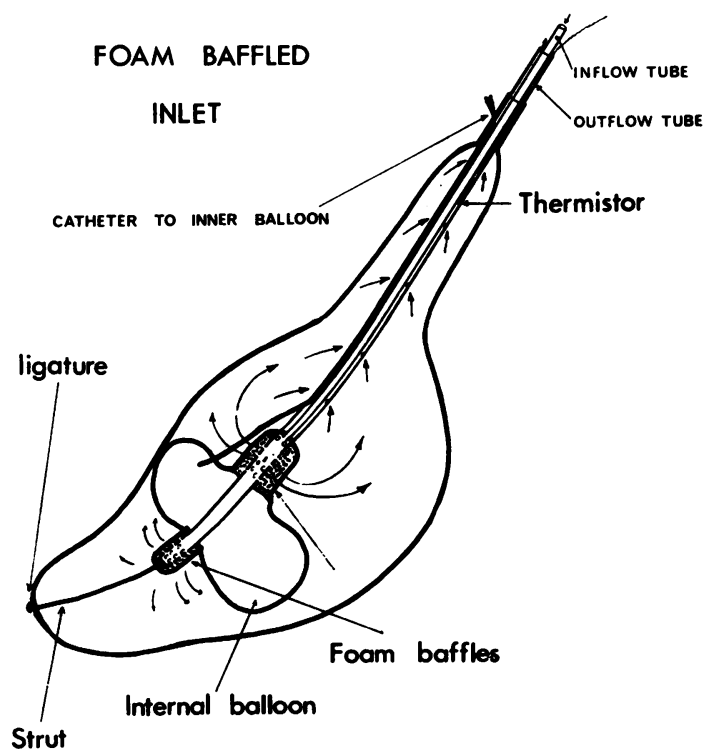

FIG. 1. Standard gastric freezing balloon with 'foambaffled' inlet device. 
recently reported (Blumgart et al., 1964) and the temperature conditions were similar to those advocated by Wangensteen and his colleagues (Wangensteen et al., 1962a and b; Peter et al., 1962).

\section{RESULTS}

The results are compared with those obtained in our study (Blumgart et al., 1964) of the standard rosette inlet device (Table I).

Antral and rectal temperatures and the temperatures of the circulating alcohol were similar in both series.

Temperatures recorded in the body of the stomach, however, were much more evenly distributed when using the foam inlet than with the standard device. Patchy solid freezing at temperatures below $-2^{\circ} \mathrm{C}$. and followed by necrosis and ulceration occurred in each of the six dogs frozen with the standard apparatus (Blumgart et al., 1964). On the other hand none of the 10 animals frozen with the modified inlet showed solid freezing at the end of the procedure or gastric ulceration three to five days later. Temperatures in the body of the stomach using the foam-baffled inlet were comparable to those recorded at a distance from solidly frozen sites using the rosette inlet.

Several attempts were then made to lower the mean temperature of the body of the stomach closer to $-2^{\circ} \mathrm{C}$. in dogs frozen with the modified inlet.

Prolonging the procedure or lowering the temperature of the circulating coolant resulted in either the reappearance of patchy freezing or severe generalized hypothermia.

Colder gastric temperatures were achieved using a thinner (condom) balloon. However, not only were diffuse areas of solid freezing found but the balloons proved liable to puncture or burst.

Freezing of the greater part of the body of the stomach was finally achieved in one animal treated for a prolonged period (outflow temperature $-18^{\circ} \mathrm{C}$. to $-21^{\circ} \mathrm{C}$.) using the foam inlet and condom balloon. The animal died a few hours after recovery from the anaesthetic with massive haemorrhagic necrosis of the body of the stomach and related liver, spleen, diaphragm, and rectus muscle.

EFFECTS ON GASTRIC SECRETORY FUNCTION Five dogs (weight $18.8 \mathrm{~kg}$. to $24 \mathrm{~kg}$.) were prepared with total gastric fistulae.

The maximal $\mathrm{HCl}$ output (mEq./hour) in response to a continuous intravenous infusion of histamine acid phosphate was determined in each dog by a method similar to that described by Code (1956). Similarly, the maximal $\mathrm{HCl}$ output (mEq./half hour) in response to a single intravenous injection of soluble insulin $(0.5$ units $/ \mathrm{kg}$.) was measured.

At least three histamine and three insulin baseline tests were done in each dog. The last of these was in the week preceding 'freezing' with the standard rosette inlet (outflow temperature $-9^{\circ} \mathrm{C}$. to $-11^{\circ} \mathrm{C}$. for one hour).

The histamine tests were repeated on the fifth, twelfth, and nineteenth days after freezing but were suspended once pre-freezing levels were reached. The insulin tests were repeated on the seventh and fourteenth days after freezing. In three of the animals (dogs 1, 2, 3; Table II),

TABLE I

SUBMUCOSAL AND RECTAL TEMPERATURES AT 60 MINUTES IN SIX DOGS FROZEN USING THE STANDARD APPARATUS AND 10 DOGS USING THE FOAM-BAFFLED INLET

Temperatures $\left({ }^{\circ} \mathrm{C}.\right)$

Standard Rosette Inlet

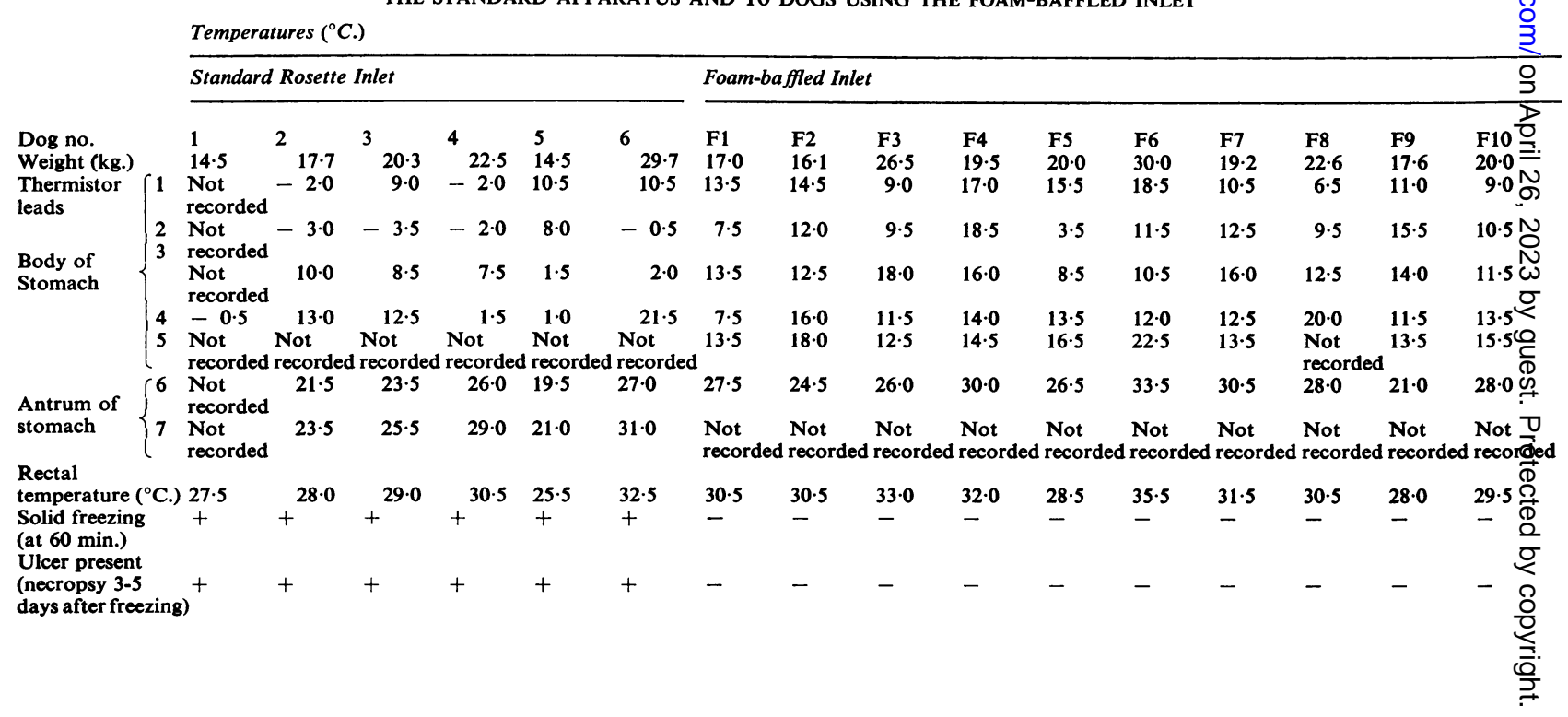


the histamine tests were repeated two months after freezing.

Within the week following the last histamine test performed after the standard 'freeze', each of the five dogs was subjected to a second 'freezing' under the same conditions but using the foam-baffled inlet.

The histamine tests were repeated five days later.

The stomach of each dog was examined using a fibreoptic gastroscope five days after both the standard and the modified procedure.

The results are shown in Tables II and III.

Good baseline levels were obtained with the histamine tests but the known (Davis and Brooks, 1962) variability of the insulin response in fistula dogs was evident in our results.

The response to histamine was incompletely suppressed for a short time after the standard freeze in three of the five dogs (dogs 1, 3, 4; Table II) but not at all in the other two. There was no effect on the secretory response to histamine following freezing with the foam-baffled apparatus (Table II). Although the secretory response to insulin was less than pre-freezing values in three of the dogs (dogs 1 , 2, 5; Table III), it was not so in the other two. All were well within pre-freezing values by 14 days.

Gastric ulcers were seen at gastroscopy in four of the five dogs following the standard freeze. Dog 2 had only a small ulcer and no lesion was seen in $\operatorname{dog} 5$. No lesion was seen after the modified procedure.

GASTRIC COOLING EXPERIMENTS USING THE NEW INLET DEVICE Submucosal temperatures were recorded in the body and antrum of the stomach and in the duodenum. In five dogs 'cooled' for two and a half hours at an outflow temperature (at the neck of the balloon) of $0^{\circ} \mathrm{C}$. to $+5^{\circ} \mathrm{C}$, remarkably even cooling of the body of the stomach was attained with a mean temperature of $16.2^{\circ} \mathrm{C}$. (standard deviation 2.92). Antral and duodenal temperatures fell little below the rectal temperature (Table IV).
TABLE III

MAXIMAL HCl ACID OUTPUT OF FIVE FISTULA DOGS IN RESPONSE TO A SINGLE INTRAVENOUS INJECTION OF SOLUBLE INSULIN

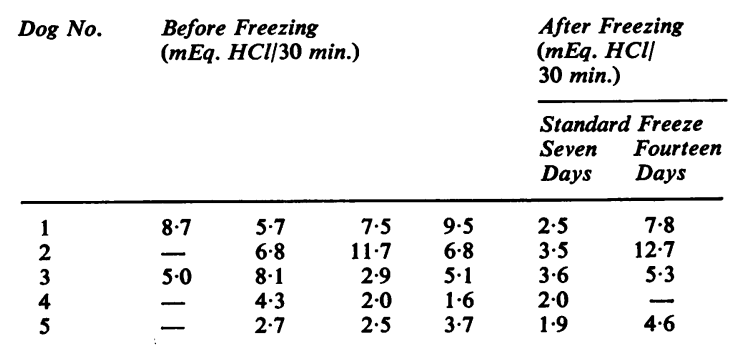

\section{TABLE IV}

SUBMUCOSAL AND RECTAL TEMPERATURES IN FIVE DOGS COOLED USING THE FOAM-BAFFLED INLET

Temperature $\left({ }^{\circ} \mathrm{C}.\right)$

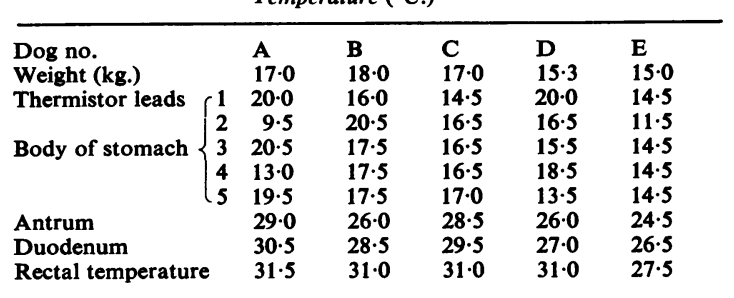

SUMMARY

Solid freezing of the canine stomach is regularly followed by necrosis and ulceration.

An apparatus has been developed which, under identical experimental conditions to the standard inlet device, cools the stomach much more evenly and produces neither solid freezing nor gross mucosal damage.

A short-lived, incomplete suppression of gastric acid secretion was found after freezing with the standard apparatus. When present it was associated

TABLE II

MAXIMAL HCl ACID OUTPUT OF FIVE FISTULA DOGS IN RESPONSE TO A CONTINUOUS INTRAVENOUS INFUSION OF HISTAMINE ACID PHOSPHATE

\begin{tabular}{|c|c|c|c|c|c|c|c|c|c|c|}
\hline \multirow{4}{*}{$\begin{array}{l}\text { Dog. } \\
\text { No. }\end{array}$} & \multicolumn{5}{|c|}{ Before Freezing ( $m E q . H C l / h o u r)$} & \multicolumn{5}{|c|}{ After Freezing (mEq. HCl/hour) } \\
\hline & & & & & & \multicolumn{3}{|l|}{ Days } & \multirow{2}{*}{$\frac{\text { Months }}{2}$} & \multirow{2}{*}{$\frac{\text { Days }}{5}$} \\
\hline & & & & & & 5 & 12 & 19 & & \\
\hline & & & & & & \multicolumn{4}{|c|}{ Standard Freeze } & Modified Freeze \\
\hline $\begin{array}{l}1 \\
2 \\
3 \\
4 \\
5\end{array}$ & $\begin{array}{l}34 \cdot 4 \\
52 \cdot 8 \\
- \\
- \\
-\end{array}$ & $\begin{array}{l}33.6 \\
49.0 \\
- \\
\overline{28.8}\end{array}$ & $\begin{array}{l}35 \cdot 0 \\
48 \cdot 4 \\
28 \cdot 8 \\
34 \cdot 0 \\
27 \cdot 2\end{array}$ & $\begin{array}{l}31 \cdot 7 \\
48 \cdot 8 \\
25 \cdot 2 \\
32 \cdot 8 \\
26 \cdot 8\end{array}$ & $\begin{array}{l}33 \cdot 2 \\
46 \cdot 0 \\
26.0 \\
34 \cdot 0 \\
31 \cdot 6\end{array}$ & $\begin{array}{l}23 \cdot 2^{1} \\
50 \cdot 4^{1} \\
12 \cdot 8^{1} \\
28 \cdot 0^{1} \\
32 \cdot 0^{1}\end{array}$ & $\begin{array}{l}36 \cdot 8 \\
\overline{23} \cdot 6 \\
34 \cdot 8 \\
-\end{array}$ & $\begin{array}{l}- \\
\overline{26} \cdot 0 \\
- \\
-\end{array}$ & $\begin{array}{l}37.6 \\
58.4 \\
26.0 \\
- \\
-\end{array}$ & $\begin{array}{l}32.5 \\
55.4 \\
24.0 \\
36.0 \\
33.2\end{array}$ \\
\hline
\end{tabular}


with gastric ulceration. No change was observed after freezing with the new inlet device.

This communication offers no support for the clinical use of gastric 'freezing' in the treatment of duodenal ulcer. If gastric 'cooling' is to be used for the treatment of massive upper gastrointestinal haemorrhage, it would seem desirable to use an apparatus known to produce fairly even cooling. The new foam-baffled inlet fulfilled this criterion when tested under 'cooling' conditions.

The hypothermia equipment was supplied by the M.R.C. and the temperature recording apparatus by the United Sheffield Hospitals Research Endowment Fund.

The authors are grateful to Professor A. W. Kay for valuable advice throughout and to the staff of the Field Laboratories, Sheffield University, for technical assistance.

\section{REFERENCES}

Artz, C. P., McFarland, J. B., and Fitts, C. T. (1964). Mucosal changes following gastric freezing. Amer. J. Surg., 107, 277-282.

Blumgart, L. H., Kay, A. W., Naylor, F. D., and Kugler, J. (1964). Experimental studies with gastric freezing. Gastroenterology, 47, 291-305.
Code, C. F. (1956). Histamine and gastric secretion. In Ciba Foundation Symposium on Histamine, edited by G. E. W. Wolstenholme and C. M. O'Connor, pp. 189-219. Churchill, London.

Davis, R. A., and Brooks, F. F. (1962). Variability of gastric secretory response to insulin hypoglycemia in fistulous beagle dogs. Amer. J. Physiol., 202, 1070-1072.

Karacadag, S., and Klotz, A. P. (1964). Side effects and complications of gastric freezing. J. Amer. med. Ass., 188, 1151-1153.

Lippman, H. N., Morgenstern, L., and Panish, J. F. (1964). Etiology and prevention of gross mucosal lesions seen after gastric freezing. Ibid., 187, 265-269.

McIlrath, D. C., Hallenbeck, G. A. Allen, H. A., Mann, C. V., Baldes, E. J., Brown, A. L., Jr. and Rovelstad, R. A., (1963). Gastric freezing: an experimental study. Gastroenterology, 45, 374-383.

Peter, E. T., Bernstein, E. F., Sosin, H., Madsen, A. J., Walder, A. I., and Wangensteen, O. H. (1962). Technique of gastric freezing in the treatment of duodenal ulcer. J. Amer. med. Ass., 181, 760-764.

Scott, B. H. W. Jr., Shull, A. J., O'Neill, J. A. Jr., and Richie, R. E., (1964). Experimental and clinical appraisal of gastric freezing for duodenal ulcer. Ann. Surg., 159, 769-786.

Wangensteen, O. H., Peter, E. T., Nicoloff, D. M., Walder, A. I., Sosin, H., and Bernstein, E. F. (1962a). Achieving 'physiological gastrectomy' by gastric freezing: a preliminary report of an experimental and clinical study. Ibid., 180, 439-444.

$\longrightarrow$ - - Bernstein, E. F., Walder, A. I., Sosin, H., and Madsen, A. J. (1962b). Can physiological gastrectomy be achieved by gastric freezing? Ann. Surg., 156, 579-591.

White, R. R., Hightower, N. C., Jr., and Adalid, R. (1964). Problems and complications of gastric freezing. Ibid., 159, 765-768.

\section{The June 1965 Issue \\ THE JUNE 1965 ISSUE CONTAINS THE FOLLOWING PAPERS}

Pseudo-membranous colitis s. J. M. GOULSTON and V. J. MCGOVERN

Ischaemic enterocolitis v. J. MCGOVERN and S. J. M. GOULSTON

Cutaneous abacterial inflammatory reaction in patients with ulcerative colitis PER WOLF-JÜRGENSEN, POUL ANTHONISEN, and POVL RIIS

Number, size, and distribution of Peyer's patches in the human small intestine J. S. CORNES

Part I The development of Peyer's patches

Part II The effect of age on Peyer's patches

Macroautoradiography with radiophosphorus in cancer of the stomach O. GREGOR, O. ANDRÝSEK, B. BEDNÁk, L. HANfK, O. VANĚČKOVÁ, and L. Š́STEK

Simple and complicated hypertrophic pyloric stenosis in the adult $w$. MILO KEYNES

Pyloric stenosis in adults: A clinical and radiological study of 100 consecutive patients LOUIS KREEL and HAROLD ELLIS

Gastric emptying and secretion in patients with diabetes mellitus PAMELA AYLETT
Effect of age on liver function with particular reference to bromsulphalein excretion EILEEN N. THOMPSON and ROGER WILLIAMS

ABO blood group and secretor status in relation to clinical characteristics of peptic ulcers M. J. S. LANGMAN and $R$. DOLL

Acidity of gastric contents during nocturnal intragastric drip therapy in patients with duodenal ulcer J. E. LENNARD-JONES, J. C. D. HART, and PAMELA B. WILCOX

Malignant Zollinger-Ellison syndrome in a Bantu woman with a prolonged remission :fter gastric radiotherapy S. BANK, I. N. MARKS, R. SEALY, J. H. LOUW, and W. SILBER

Intestinal mucosa in the Zollinger-Ellison syndrome J. A. PARRISH and D. C. RAWLINS

A sequential trial of tolbutamide in hypoproteinaemia in adults G. S. MUTALIK and INDER SINGH

Selective vagal effects on the intestinal phase of gastric secretion MICHAEL D. MIDDLETON, KEITH A. KELLY, LLOYD M. NYHUS, and HENRY N. HARKINS

Effect of vagotomy on intraluminal digestion of fat in man MEIRA FIELDS and H. L. DUTHIE

Copies are still available and may be obtained from the PUBLISHING MANAGER, BRITISH MEDICAL ASSOCIATION, TAVISTOCK SQUARE, W.C.I. price 18s. 6D. 